\section{REGIONAL REPORTS}

\author{
Big Brother due in Bebbington \\ The West Lancs, West Cheshire and North Wales Branch \\ AGM will take place on 5 February 2013 at the PGMC, \\ Clatterbridge Hospital, Bebbington, Wirral, CH63 4JY. The \\ AGM will be preceded by a lecture, 'Big Brother', given be \\ Richard Birkin, Head of Regional Services at the British \\ Dental Association (BDA) and will cover how the NHS \\ monitors you: past, present and future. The presentation \\ will include advice on NICE guidelines and record keeping. \\ Tea and coffee will be available from 6pm, with the lecture \\ commencing at $6.30 \mathrm{pm}$.
}

\section{Resounding success in Leicester}

On 8-9 November 2012 the 16th annual conference of the National Association of Dental Advisers (NADA) was held in Leicester and was a resounding success. Presentations were given by Sue Gregory, Sam Illingworth and Collette Bridgeman, John Milne (chair of the GDPC), the GDC, NCAS and the Health Service Ombudsman.

At the AGM it was agreed that with the continued success of NADA it would be beneficial to the profession if NADA membership was open to all clinicians who give advice, including corporate bodies, defence organisations and professional bodies. www.nada-uk.org

\section{Current challenges in Cape Town}

At the 7th Triennial Meeting of the Commonwealth Dental Association (CDA) held in Cape Town, South Africa, in November, the CDA installed new officers for 2012-2014 and agreed to a constitutional change to move from triennial to biennial general meetings. The CDA held a plenary session followed by a workshop chaired by Professor Samarawickrama on the subject of Oral health and oral disability in the elderly. Dr Sue Greening, Dr Tope Esan and Dr Graham Gilmore presented current challenges and possible approaches to this issue. www.comdental.org

\section{LPN forms in Thames Valley}

PCTs within Berkshire, Oxfordshire and Buckinghamshire have recently begun testing the outline proposals for a Local Professional Network (LPN) across dentistry by forming the Thames Valley Dental LPN. The network is made up of local clinicians, a medical director, commissioning managers and a consultant in dental public health.

Dental LPNs will have an important role in informing the decisions which commissioners will make regarding all dental services from April 2013.

To register interest in the next Thames Valley Dental LPN forum meeting on 17 January 2013 email tvd.Ipn@nhs.net.

\title{
DENTAL CHAIRS PRESERVED IN RADIOACTIVE SILT
}

October's issue of $X$-Ray Magazine, an international scuba diving publication, featured a photograph of a dental chair submerged on the wreck of the USS Saratoga.

According to X-Ray Magazine, the USS Saratoga was first commissioned in 1925 and was a 40,000-ton, 268-metre long aircraft carrier touring the Pacific, Nicaragua, San Diego, Hawaii, Guadalcanal and the Marshall Islands. After World War II she was decommissioned and sank as a result of nuclear testing at

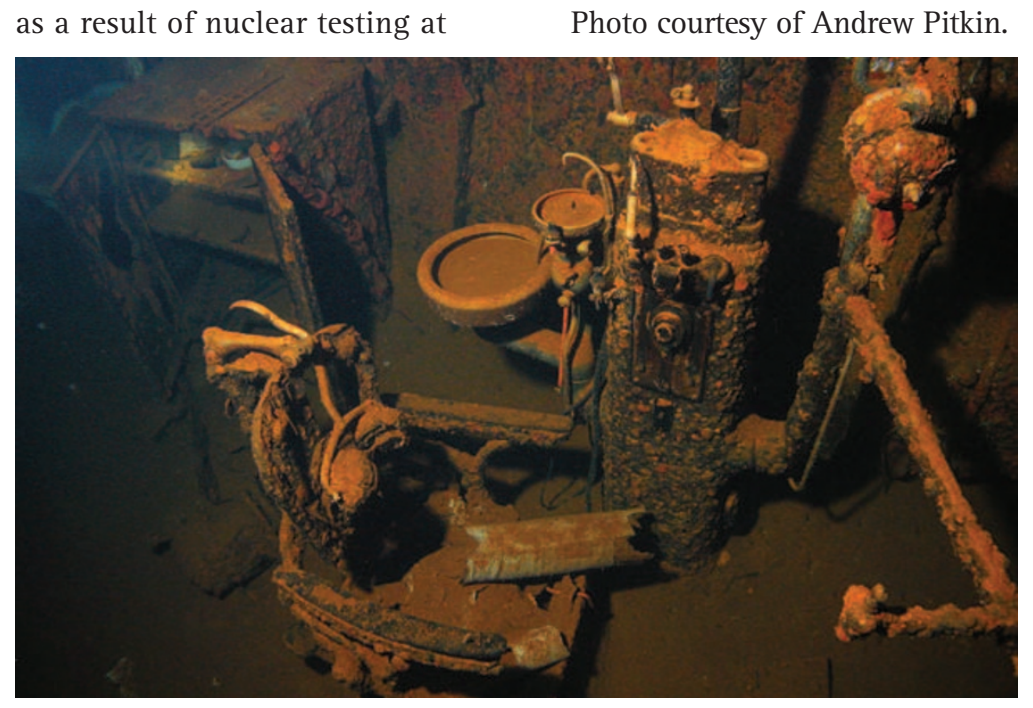

Bikini Atoll in the Pacific Ocean.

The diver writing in $X$-Ray Magazine, Pete Mesley, reports: 'One of the dives that totally blew my mind was the dentist's surgery and sick bay. [...] Three dentist chairs sat in the room, completely kitted out with drills, rinse bowls, even head phones for the patients. Perfectly preserved. Everything was covered in the finest red rusty silt, probably highly radioactive if you dug deep enough into it.' Photo courtesy of Andrew Pitkin.

\section{GDC UPDATE}

The GDC has launched more accessible versions of its patient information. The 'Smile EasyRead' patient information leaflet features larger font, pictures to support and help explain the text, shorter sentences and natural language.

- The GDC's consultation on its proposed new standards for dental professionals in the UK closes at the end of this month. The GDC is keen to hear from as many people as possible: www.gdc-uk.org/GDCcalendar/ Consultations/Pages/Review-of-
Standards-Consultation.aspx.

- The GDC is urging employers to help remind DCPs about the approaching CPD deadline in July 2013. Over 40,000 DCPs will reach the end of their first five-year CPD cycle on 31 July 2013 and must have completed 150 hours of CPD 50 of them verifiable.

- The GDC is highlighting a warning from the Medicines and Healthcare Products Regulatory Agency (MHRA) about the Tianjie Dental Falcon scanner which has been shown to lack sufficient shielding in the X-ray tube.

\section{REMEMBERED THROUGH RECIPES}

A recipe book written by the late Richard Horner, who established the first Mouth Cancer Action Week, is available as a download in aid of mouth cancer awareness. The Duck House Cookbook is a tribute to Richard's passion for cooking and his love of life.

Including recipes such as 'Cornish brill with crispy squid and potato salad', the book was bequested to the British Dental Health
Foundation upon Richard's death.

For a minimum suggested donation of $£ 5$, the book can be downloaded and any donations will go to Mouth Cancer Action Month. www.justgiving.com/ The-Duck-House-Cookbook 